\title{
Factors Influencing Sample Size for Internal Audit Evidence Collection in the Public Sector in Kenya
}

\author{
Kamau, Charles Guandaru*, Kariuki, Samuel Nduati \\ *Corresponding Author: E-mail: guandaruaman@yahoo.co.uk
}

Jomo Kenyatta University of Agriculture and Technology, Kenya.

\begin{abstract}
The internal audit department has a role of providing objective assurance and consulting services designed to add value and improve an organization's operations. In performing this role the internal auditors are required to provide an auditor's opinion which is supported by sufficient and reliable audit evidence. Since auditors are not in a position to examine $100 \%$ of the records and transactions, they are required to sample a few and make conclusions on the basis of the sample selected. The literature suggests several factors which affects the sample size for audit purposes of the internal auditors in the public sector in Kenya. This research collected data from 32 public sector internal auditors. The research carried out simple regression and correlation analysis on the data collected so as to test hypotheses and make conclusions on the factors affecting the sample size for audit purposes of the internal auditors in the public sector in Kenya. The study found out that that materiality of audit issue, type of information available, source of information, degree of risk of misstatement and auditor skills and independence are some of the factors influencing the sample size determination for the purposes of internal audit evidence collection in public sector in Kenya.
\end{abstract}

Keywords: Audit evidence, Internal auditors, Materiality, Sample size.

\section{Introduction}

ISA 500 requires that the auditors should design and perform audit procedures that are appropriate in the circumstance for the purpose of obtaining sufficient and appropriate evidence. It further explains that audit evidence is necessary to support the auditor's opinion and report. It is cumulative in nature and is primarily obtained from audit procedures performed during the course of the audit. It may, however, also include information obtained from other sources such as previous audits or a firm's quality control procedures for client acceptance and continuance. In addition to other sources inside and outside the entity, the entity's accounting records are an important source of audit evidence. Auditors may not be in a position to carry out $100 \%$ examination and verification of records and transactions. Therefore auditors use sampling concept to choose a sample of records and transactions, carry out examination of the sample and use the results to draw conclusions about the fairness of a company's financial statements. Consequently, auditors can only provide assurance but not absolute assurance that the financial statements are fairly presented [1].The internal auditing standards asserts that an internal auditor has a professional duty and an ethical responsibility to evaluate carefully all the evidence and the reasonableness of his or her conclusions and, then, to decide whether further actions may be needed to protect the interests of the organization, its stakeholders, the outside community, or the institutions of society [2].Internal audit aims to increase the accountability of government ministries by ensuring transparency, validating key systems of internal control, and committing resources against key risks. To achieve this task the internal auditors are required to collect audit evidence to support their findings. Audit evidence collected is on the basis of sampling technique that helps the auditors to collect and analyze the required information. This research looks into the various factors affect the size of the sample that the auditors will select for the purpose of audit evidence collection.

\section{Statement of the Problem}

Internal auditing is defined by IIA as an independent, objective assurance and consulting activity designed to add value and improve an organization's operations. The Internal audit helps an organization achieve its objectives by bringing a systematic, disciplined approach to evaluate and improve the effectiveness of risk management, control, and governance processes [2] Internal 
auditor's opinion should be supported by sufficient and reliable audit evidence. IIA proposes that internal auditors in the process of providing assurance should carry out objective examination of evidence for the purpose of providing an independent assessment on risk management, control, or governance processes for the organization [2]. Beasley, Carcello and Hermanson [3] observed that the most common problem found in $80 \%$ of the cases, was the auditor's failure to gather sufficient audit evidence. Many of the cases which they studied involved inadequate evidence in areas such as asset valuation, asset ownership and management representations.Gathering internal audit evidence is a challenge for many auditors since they are required to carry out their work independently yet at the same time they are part of management. Attitude of the auditees towards the internal auditor complicates the process of audit evidence gathering. This study therefore sought to explore the factors affecting the sample size for internal audit evidence collection in public sector in Kenya.

\section{Objectives of the Study}

- To find out the effect of materiality on the sample size for internal audit evidence collection

- To identify the effect of type of information on the sample size for internal audit evidence collection

- To identify the effect of source of information on the sample size for internal audit evidence collection

- To evaluate the effect of degree of risk of misstatement on the sample size for internal audit evidence collection

- To determine the effect of auditor skills and independence on the sample size for internal audit evidence collection

\section{Hypothesis of the Study}

The null hypotheses are stated as follows.

- Materiality of the audit issue has no effect on the sample size for internal audit evidence collection.

- There is no relationship between type of information available and the sample size for internal audit evidence collection.

- There is no relationship between source of information and the sample size for internal audit evidence collection.

- There is no relationship between degree of risk of misstatement and the sample size for internal audit evidence collection.

- There is no relationship between auditor skills \& auditor independence and the sample size for internal audit evidence collection.

Justification
Audit evidence gathering is fundamental in carrying out audit engagements. It's on the basis of the audit evidence gathered that the internal auditor makes conclusions about an audit issue. Gathering audit evidence is a complex activity which depends on a number of factors, understanding these factors is important for the internal auditors. This research may be of great significance in improving the performance of the auditors in the public sector.

\section{Conceptual Framework}

Conceptual framework is a visual or written product that explains graphically or in narrative form, the main things to be studied. It describes the key factors, concepts, and variables and the presumed relationship among them [4]. According to Nachmias, "the variable that the researcher wishes to explain is the dependent variable." The independent variable causes or explains changes in the dependent variable. In this research, the internal audit evidence was the dependent variable.Several factors may influence the internal audit sufficiency in public sector in Kenya. These factors become the independent variables in this research. They include:

\section{Materiality of the Audit Issue}

The internal audit evidence required largely depends on the materiality level of the audit issue being considered. The researcher expected that the higher the materiality level the higher the sample size required for audit evidence collection.

\section{Type of Information Available}

The researcher expected that the type or nature of information available will affect the sample size that will be required for internal audit evidence collection.

\section{Source of Information}

The information source also affects the sample size required for internal audit evidence collection. The size of the sample will depend on whether the information is from the organization, third parties, experts or the general public.

\section{Degree of Risk of Misstatement}

The internal auditor provides reasonable assurance on the operations of the organization. If there is high risk of misstatement in the records, the auditor is required to increase the size of audit sample to be considered.

\section{Auditor Skills and Independence}

Internal auditors as individuals have more skills in some areas as compared to other areas. Likewise 


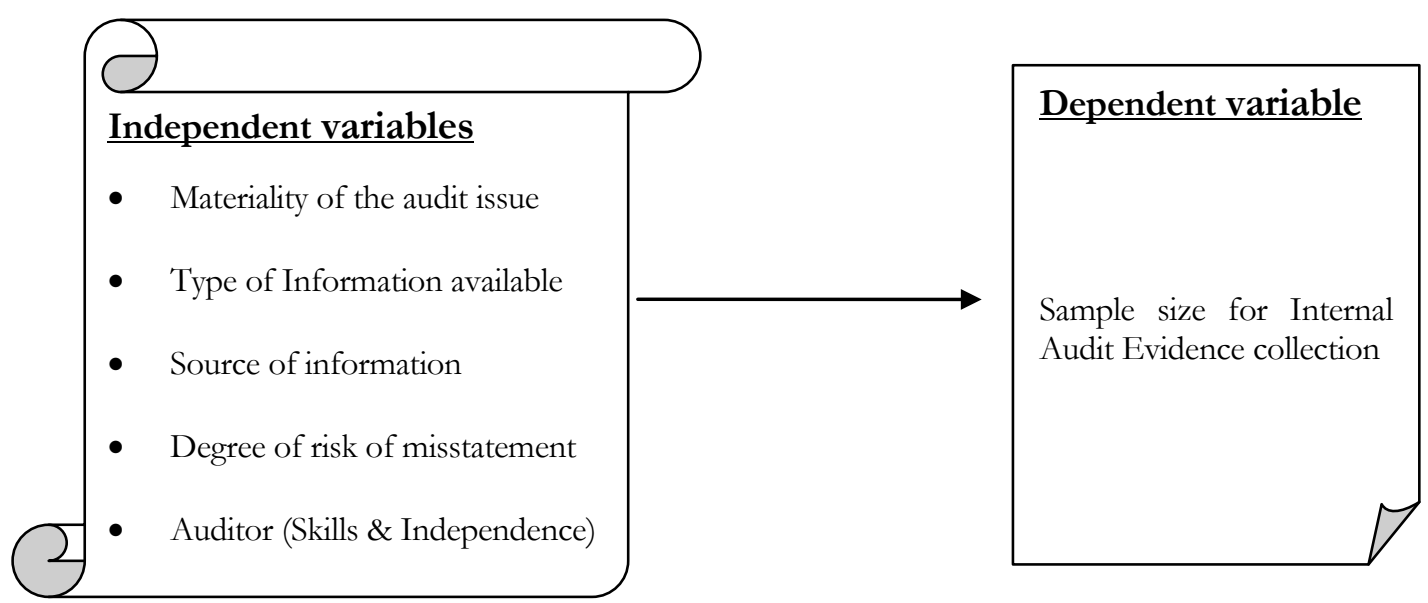

Fig. 1: The independent variable causes or explains changes in the dependent variable

they enjoy audit independence in some situations as compared to some others. The researcher therefore expected that when the skills of an auditor in an area are high, less sample will be selected and vice versa. Further if the auditor enjoys high audit independence in a situation, the sample size required might be less.

\section{Literature Review}

\section{Theoretical Framework}

Evidence Theory is a branch of the mathematics of uncertain reasoning that entails profound epistemological differences with respect to Probability Theory. In fact, its paradigmatic situation is the judge who must evaluate testimonies, rather than the gambler who must evaluates odds. Unlike a gambler, who faces a definite set of possibilities, a judge may be forced to change her evaluation because of novel possibilities suggested by unexpected testimonies. In this sense, Evidence Theory provides a formalization of some among Shackles intuitions. While the details of the connections between Shackle's theory and Evidence Theory have been explored elsewhere, this article is devoted to a detailed explanation of the working of Evidence Theory. An example is discussed in detail and several domains of application are briefly sketched [5].Toba [6] explained a general theory of evidence as the conceptual foundation of auditing theory. The theory states that "auditing is a systematic process of objectively obtaining and evaluating evidence regarding assertions and established criteria and communicating the results to interested users". This statement emphasizes on objectively collecting audit evidence as a foundation of good auditing practice. The approach was first advanced by Toba focuses on the relationship between concepts of evidence and the propositions to be proved in a financial statement audit. The process of splitting up the ultimate proposition ("fair presentation") into a number of elementary propositions that must be supported by evidence is described. Gronewold [7] advances a theory on probative value of audit evidence where he asserts that auditor uses audit evidence to draw conclusions about the relevant reality, which cannot be observed anymore. He argued that how well a correct recognition of the relevant reality can be achieved, depends on the probative value of the evidence, which in turn depends on the accuracy of the evidence creation and transmission process. This theory considered source of audit evidence, evidence creation and transmission process, characteristics of evidence and the auditor as the variables affecting the probative value of audit evidence.

\section{Materiality of the Audit Issue}

When conducting audit, the auditor should consider materiality of the audit issues and its relationship with the audit risk. If the audit risk is high then more audit evidence is required. An audit issue is considered material if its misstatement could influence the economic decision of the users. Materiality also depends on the size and nature of the item judged in the particular circumstance. Materiality also has a quantitative thresh hold or a cutoff point. Assessment of what is material is a matter of professional judgment [8]. Bernardi and Pincus [9] argued that while auditor materiality judgments differ, these differences were not statistically significantly related to either fraud risk judgments or the amount of evidence the auditors chose to examine before rendering their judgments. Chong, [10] informs that there is great concern about the applicability of materiality in the auditing profession. Various materiality guidelines have been recommended by both academic researchers and accounting bodies, but the Auditing Practices Board in the UK has yet to recommend a guideline of its own. Materiality is a consideration in many audit decisions.

\section{Type of Information Available}


Moeller [11] argued that an internal auditor will encounter multiple types of evidence that can be useful in developing audit conclusions. He also evidence than the informal audit evidence. Audit sampling is a key approach for auditors when faced with large volume of information to select from [12]. There are various types of information that the auditor may require for his/ her audit evidence.

\section{Source of Information}

Moeller [11] explained that audit evidence obtained through observation and confirmations by the auditor is more reliable that the evidence collected through inquiry. He also argued that evidence from corroborative materials is stronger than evidence from underlying statistics. Evidence created by the actual system is stronger than the evidence derived from a support system. Auditor's personal work is more reliable than the supplied or second hand information. Gupta, [14] explains that the reliability of audit evidence largely depends on its source. He further explains that external evidence is more reliable than internal evidence, internal evidence is more reliable when related internal control is satisfactory, written information is more reliable than the oral information and that information gathered by the auditor himself is more reliable than information obtained from third parties.

\section{Degree of Risk of Misstatement}

When the risk of material misstatement is high, more persuasive evidence is required together with individual auditor's judgment [15]. Bragg [16] asserts that the greater the risk of material misstatement, the greater the extent of substantive procedures required to collect audit evidence. He also adds that the auditors judgment as to what constitutes sufficient audit evidence is influenced by significance of the potential misstatements in the relevant assertion and likelihood of its having material effect. The degree of risk of misstatement may be affected by the nature of item, adequacy of internal controls, nature and size of business carried on by entity, situations which may exert an unusual influence on managers and financial position of the entity [14].

\section{Auditor Skills and Independence}

Goodwin and Yeo [17] noted that there were two factors affecting audit independence and objectivity. The first factor affecting the organizational independence of the internal audit function was its relationship with the audit committee. The second was the use of the function argued that written materials provide stronger audit evidence than oral information. Formal and documented information gives stronger audit This information includes, oral and written materials, authoritative documents, formal and informal information, etc [13]. ISA 500 indicates that reliability of audit evidence depends on its sources and perhaps its nature.

as a management training ground. It is argued that this practice might affect individual objectivity because internal auditors may be reluctant to withstand pressure from an auditee who could be their future supervisor. A survey of chief internal auditors in Singapore was undertaken to establish current practice in these areas and to identify relationships between these variables. A strong relationship between the audit committee and the internal audit function was found, with the level of interaction being greater when the audit committee was comprised solely of independent directors. The use of the internal audit function as a management training ground was also found to be quite widespread in Singapore. The wide range of skills is necessary to fulfill management's expectations of the internal audit function and there exists disparity between individual internal audit managers on a number of issues, including skills [18]. The level of skills possessed by an internal auditor may determine the amount of audit evidence that he or she might require to form an appropriate audit conclusion.

\section{Research Gap}

The literature reviewed indicated that quite a lot have been documented on audit evidence issues. However, not much work has been done on sample size determination for the purpose of audit evidence collection. This study will not only provide a perspective on the factors that affect sample size for internal audit evidence collection but will provide further empirical information on factors affecting audit sample determination.

\section{Research Design and Methodology}

\section{Research Design}

Research design is a program that guides the investigator in collecting, analyzing and interpreting data. It assists the researcher to determine the objectives of research, subjects of research, the sample size, the data to be collected, the procedures of collecting and recording that data, the procedures for analyzing that data and how the data will be interpreted and presented [19].

\section{Population and Sample}


The research population is public sector auditors working in Kenya. There are more than one thousand public sector internal auditors in Kenya. Since the research design employed is a survey, the researcher circulated 35 questionnaires to his friends through their e-mails. The researcher employed convenience sampling technique in this study.

\section{Research Variables}

In this research, Materiality of audit issue, type of information available, source of information, degree of risk of misstatement and auditor skills and independence are considered as independent variables, and sample size for internal audit evidence collection as the dependant variable.

\section{Data Collection}

The data was collected from internal auditors working in the public sector in Kenya. The questions regarding the sample size were in form of 6 point likert scale measured as follows: None (0), Very small (1), Small (2), Medium (3), Large (4) and Very Large (5). Data was collected on all the dependent and independent variables with an aim of testing the five hypotheses indicated in section 1.3 of this research. The reliability of the questionnaire was measured using the cronbach alpha which was computed as follows:

$\alpha=\frac{k}{k-1}\left(1-\frac{\sum s_{i}^{2}}{S^{2}}\right)=\frac{k}{k-1}\left(1-\frac{\sum\left(p_{i} q_{i}\right)}{S}\right)$

$\alpha=6 /(6-1) *(1-5.327 / 14.883)=77.05 \%$

According to Kline [20] a rule of thumb in using Cronbach alpha indicates that a coefficient of between $70 \%$ and $80 \%$ is acceptable. The researcher therefore concluded that the data collected using the questionnaire was statistically suitable for analysis on the basis of resulting cronbach alpha coefficient.

\section{Research Model}

The research had one dependent variable which was the sample size for audit evidence collection and five independent variables (Materiality, type of information, source of information, degree of risk of misstatement and auditor's skills \& independence) as derived from the five hypotheses. This research adopted a simple regression model based on the first independent variable i.e. materiality levels due to the problem of multicollinearity among the independent variables.

The research model was specified as follows:

$\mathrm{S}=\mathrm{a}+\mathrm{b}_{1} * \mathrm{M}+\mathrm{e}$

Where: $\mathrm{S}$ is the sample size for audit collection
$\mathrm{M}$ is the materiality level of the audit issue $\mathrm{e}$ is the stochastic error term $a$ and $b_{1}$ are regression coefficients

\section{Data Presentation and Analysis}

The research targeted a sample of 35 public internal auditors in Kenya. 32 public internal auditors contributed to the research by filling in the questionnaires. This represented a response rate of $91.4 \%$. Therefore sample size for this study for the purpose of analysis was 32 public internal auditors. The data was analyzed in two ways, first using simple linear regression between sample size for audit evidence collection and materiality levels. Secondly the data was analyzed using correlation analysis for the purpose of testing hypotheses.

\section{Regression Analysis}

The data collected was expanded for high materiality, medium materiality and low materiality. This means that sample size, $\mathrm{n}$ for the purpose of regression was 96 i.e. 32 multiplied by 3 . The researcher regressed materiality levels on sample size and the following were the results

Table1: Regression statistics

\begin{tabular}{|c|c|}
\hline Multiple R & 0.896 \\
\hline R Square & 0.803 \\
\hline Adjusted & \\
\hline Square & 0.801 \\
\hline Standard Error & 0.366 \\
\hline Observations & 95 \\
\hline
\end{tabular}

The coefficient of determination ( $\mathrm{R}$ Square) of 0.803 showed that the predictability strength of the model is very high. The regression results therefore indicated that materiality level was a good determinant of the sample size to be considered for the purposes of audit evidence collection. The ANOVA table further described that the strength of the regression model specified was high. This was because $\mathrm{F}$ values were very high and the $p$ value was almost zero. Since the significance level for analysis used in this research was 0.05 i.e. $95 \%$ confidence level, the $p$ value of zero was within the region of high predictability of the model specified.

The model specified was:

$\mathrm{S}=\mathrm{a}+\mathrm{b}_{1} * \mathrm{M}+\mathrm{e}$

From the table above a, which is the y intercept was 1.64 and $b_{1}$ was 0.897

Therefore $\mathrm{S}=1.64+0.897 \mathrm{M}+\mathrm{e}$ 
When the level of materiality is low $(M=1)$ the sample size will be small (2) or medium (3) as shown below:

$\mathrm{S}=1.64+0.897 \mathrm{M}$

$\mathrm{S}=1.64+0.897(1)$

$\mathrm{S}=2.537$ (i.e. between 2 and 3)
When the level of materiality is Medium $(\mathrm{M}=2)$ the sample size will be medium (3) or large (4) as shown below:

$\mathrm{S}=1.64+0.897 \mathrm{M}$

$\mathrm{S}=1.64+0.897(2)$

$\mathrm{S}=3.434$ (i.e. between 3 and 4)

When the level of materiality is High $(\mathrm{M}=3)$ the sample size will be Large (3) or Very Large (4) as shown below:

Table 2: The ANOVA table for the regression results is as per shown below

\begin{tabular}{lllllc}
\hline & $\boldsymbol{d} \boldsymbol{f}$ & $\boldsymbol{S S}$ & $\boldsymbol{M S}$ & $\boldsymbol{F}$ & Significance $\boldsymbol{F}$ \\
\hline Regression & 1 & 50.690 & 50.690 & 378.855 & 1.46 X $10^{-34}$ \\
Residual & 93 & 12.443 & 0.134 & & \\
Total & 94 & 63.133 & & & \\
\hline
\end{tabular}

Table 3: ANOVA

\begin{tabular}{lllllll}
\hline & Coefficients & Standard error & $\boldsymbol{t}$ Stat & $\boldsymbol{P}$-value & Lower 95\% & Upper 95\% \\
\hline Y Intercept & 1.640 & 0.100 & 16.407 & $3.34 \times 10^{-29}$ & 1.442 & 1.839 \\
$\mathrm{~b}_{1}$ & 0.897 & 0.046 & 19.464 & $1.46 \times 10^{-34}$ & 0.806 & 0.989 \\
\hline
\end{tabular}

$\mathrm{S}=1.64+0.897 \mathrm{M}$

$\mathrm{S}=1.64+0.897(3)$

$\mathrm{S}=4.331$ (i.e. between 4 and 5)

\section{Hypothesis Testing}

The researcher used correlation analysis to test hypothesis. Since the sample size used in analysis was 96, normal probability distribution statistic was used in the analysis. For all the five hypotheses the decision criteria was as follows.

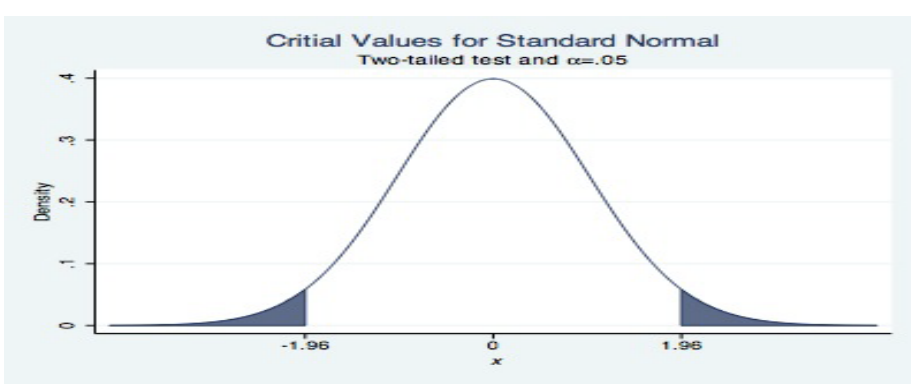

Fig.2: Hypothesis testing

The null hypothesis $\left(\mathrm{H}_{0}\right)$ was rejected for observed $\mathrm{z}$ values which were greater than $|1.96|$.

\section{Hypothesis One}

The first hypothesis stated that materiality of the audit issue has no effect on the sample size for internal audit evidence collection (i.e. $\mathrm{H}_{0}: \mathrm{b}_{1}=0$ ). The regression results presented in section 5.1 above indicated that materiality level had high influence on the sample size for internal audit evidence collection as shown by the $\mathrm{F}$ static and the $\mathrm{p}$ value. The observed $\mathrm{z}$ for materiality (20.61) was greater than the critical $\mathrm{z}$ (1.96), the null hypothesis $\left(\mathrm{H}_{0}\right)$ was rejected and alternative hypothesis $\left(\mathrm{H}_{1}\right)$ accepted. The researcher therefore concluded that materiality levels of an audit issue significantly affect the size of the sample to be selected for audit evidence collection. The level of materiality was measured using the level of funding, expenditure, contribution of the audit issue to organizations operations and public sensitivity of the issue under audit. These issues according to this research significantly determine or affect the sample size selection for the purpose of internal audit evidence collection.

\section{Hypothesis Two}

The second hypothesis stated that there was no relationship between type of information available and the sample size for internal audit evidence collection (i.e. $\mathrm{H}_{0}: \mathrm{Ys}_{\mathrm{s}}$ it $=0$ ). Since the observed $\mathrm{z}$ for type of information (20.96) was greater than the critical $\mathrm{z}$ of 1.96 , the researcher rejected the null hypothesis $\left(\mathrm{H}_{0}\right)$ and accepted the alternative hypothesis $\left(\mathrm{H}_{1}\right)$. The researcher therefore concluded that there was a statistically significant relationship between the type of information available and the sample size for internal audit evidence collection. Most of the respondents indicated that oral and informal types of information required smaller sample sizes than the formal and written types of information. This could be explained by an assumption that the latter group is more reliable than the former group for the purposes of making audit conclusions based on the evidence.

\section{Hypothesis Three}

This hypothesis stated that there was no relationship between source of information (evidence) and the sample size for internal audit evidence collection (i.e. $\mathrm{H}_{0}: \mathrm{Ys}_{\mathrm{s}}$, is $=0$ ). The observed $\mathrm{z}$ 
for source of information (17.91) was greater than the critical z (1.96), hence the null hypothesis $\left(\mathrm{H}_{0}\right)$ was rejected and alternative hypothesis $\left(\mathrm{H}_{1}\right)$ accepted. The researcher therefore concluded that there was a statistically significant relationship between the source of information and the sample size for internal audit evidence collection.

Table 4: The summary table for the observed $\mathrm{z}$ values in relation to the five hypotheses was as follows

\begin{tabular}{lcccc} 
& Correlation & Observed z & Critical z & Decision \\
\hline Sample size for audit evidence & 1 & - & & \\
Materiality & 0.8954303 & 20.61 & 1.96 & ${\text { Reject } \mathrm{H}_{0}}$ \\
Type of information & 0.8986844 & 20.96 & 1.96 & Reject $\mathrm{H}_{0}$ \\
Source of information & 0.8641963 & 17.91 & 1.96 & ${\text { Reject } \mathrm{H}_{0}}$ \\
Risk of misstatement & 0.8954303 & 20.61 & 1.96 & Reject $\mathrm{H}_{0}$ \\
Auditor skills and independence & -0.86395 & 17.90 & 1.96 & Reject $\mathrm{H}_{0}$ \\
\hline
\end{tabular}

\section{Hypothesis Four}

The fourth hypothesis stated that there was no relationship between degree of risk of misstatement and the sample size for internal audit evidence collection (i.e. $\mathrm{H}_{0}: \mathrm{Y}_{\mathrm{s}, \mathrm{rs}}=0$ ). Since the observed $\mathrm{z}$ for degree of risk of misstatement (20.61) was greater than the critical $\mathrm{z}$ of 1.96 , the researcher rejected the null hypothesis $\left(\mathrm{H}_{0}\right)$ and accepted the alternative hypothesis $\left(\mathrm{H}_{1}\right)$. The researcher therefore concluded that there was a statistically significant relationship between the degree of risk of misstatement and the sample size for internal audit evidence collection. Large number of respondents indicated that smaller sample sizes would be selected when the degree of risk of misstatement was low and large sample sizes when the risk is high.

\section{Hypothesis Five}

This hypothesis stated that there was no relationship between auditor skills \& auditor independence and the sample size for internal audit evidence collection (i.e. $\mathrm{H}_{0}: \mathrm{Ys}_{\mathrm{s}, \mathrm{sk}}=0$ ). The observed $\mathrm{z}$ for auditor skills and auditor independence (17.90) was greater than the critical $\mathrm{z}$ (1.96), hence the null hypothesis $\left(\mathrm{H}_{0}\right)$ was rejected and alternative hypothesis $\left(\mathrm{H}_{1}\right)$ accepted. The researcher therefore concluded that there was a statistically significant relationship between the auditor skills \& auditor independence and the sample size for internal audit evidence collection. The respondents indicated that they required smaller sample sizes for audit evidence collection when they possessed higher skills in an area of audit and when the auditor independence is high, likewise larger sample sizes were required where the skills level and auditors independence was low[21-24].

\section{Summary, Discussion and Conclusion}

\section{Summary}

The respondents indicated that information from the public, non experts and third parties required lesser sample size than information from organization and from experts. This can also be attributed to reliability of the information source.
The study found out that materiality of audit issue which is measured by: level of funding and expenditure; contribution of audit issue to organizations operations; and public sensitivity of the audit issue affect the sample size determination for the purposes of internal audit evidence collection. The study further observed that there was a statistically significant relationship between the sample size for audit evidence collection and materiality levels, type of information available, source of information, degree of risk of misstatement and auditor's skills and independence.

\section{Discussion}

The researchers observed that the level of funding, expenditure level of the audit issue, contribution of the audit issue to organizations operations and public sensitivity of the audit issue were the measure that determine materiality level. Materiality of the audit issue affects the sample size for audit purposes of the internal auditors in the public sector in Kenya. The study found out that there is a statistically significant relationship between the type of information (such as oral, written, formal and informal information) and the sample size for internal audit evidence collection in public sector in Kenya. The study further established that the source of information which includes third parties, general public, experts, and organization, correlates strongly with the sample size for audit purposes of the internal auditors in the public sector in Kenya. The study established that the degree of risk of misstatement correlates with the sample size for audit purposes of the internal auditors in the public sector in Kenya. It also established that there was a strong negative relationship between auditor skills and independence with the sample size for audit purposes of the internal auditors in the public sector in Kenya. The discussion concludes that materiality, type of information, source of 


\section{Availlable online at www.managementjournal.info}

information, degree of risk of misstatement and auditor's skills and independence are factors that influence the sample size for audit purposes of the internal auditors in the public sector in Kenya.

\section{Conclusion}

The study established that materiality of audit issue, type of information available, source of information, degree of risk of misstatement and auditor skills and independence are some of the factors influencing the sample size determination

\section{References}

1. Eilifsen A, Messier WF, Glover SM, Prawitt DF (2006) Auditing and Assurance Services. International Edition. Glasgow: McGraw Hill Education.

2. The Institute of Internal Auditors (2010) The Professional Practices Framework. Florida, USA: Altamonte Springs.

3. Beasley MS Carcello, Joseph V, Hermanson DR (2001) Top ten audit deficiencies, lessons learned from SEC fraud related cases. J. Accountancy 191:636.

4. Maxwell Joseph A (2005) Qualitative research design: an interactive approach. California, USA: Sage Publications inc.

5. Fioretti G (2009) Evidence Theory as a Procedure for Handling Novel Events. Metroeconomica 60: 283-301. doi: 10.1111/j.1467-999X.2008.00331.x.

6. Toba Yoshihide (1975) A General Theory of Evidence as the Conceptual Foundation in Auditing Theory. The Accounting Review. 50(1):7-24

7. Gronewold Ulfert (2006) Probative value of audit evidence: A framework and synthesis. J. Forensic Accounting VII:345-94

8. Ainapure V, Ainapure M (2009)Auditing and Assurance $2^{\text {nd }}$ Ed. New Delhi: PHI Learning Private Ltd, 252

9. Bernardi RA, Pincus, KV (1996) The relationship between materiality thresholds and judgments of fraud risk. Managerial Finance, 22(9:1-15.

10.Chong HGin (1992) Auditors and materiality. Managerial Auditing Journal 7:5.

11. Moeller Robert R (2009) Brink's Modern Internal Auditing: A Common Body of Knowledge. New Jersey: John Wiley \& Sons Inc.

12.Moeller Robert R (2010) IT Audit, Control and Security. New Jersey: John Wiley \& Sons Inc. for the purposes of internal audit evidence collection in public sector in Kenya. In conclusion, materiality levels may be a good predictor of the sample size to be selected by internal auditors in public sector in Kenya. Areas for further research could include areas such as financial implications of audit evidence, co-operation between the auditor and client and political influence as factors that influence audit's sample size.

13.Basu SK (2009) Auditing. New Delhi: Dorling Kindersly pvt. Ltd.

14.Gupta Kamal (2005) Contemporary Auditing, $6^{\text {th }} \mathrm{Ed}$. New Delhi: Tata-McGraw Hill Publishing Co. ltd.

15.Rittenberg Larry E, Johnstone K, Gramling Audrey A, Schweiger Bradley (2009) Auditing: a business risk approach. Mason, OH: South Western Cengage Learning.

16. Bragg SM (2011) Wiley's practitioners guide to GAAS 2012. New Jersey: John Wiley \& Sons Inc.

17.Goodwin J, Yeo TW (2001) Two factors affecting internal audit independence and objectivity: Evidence from Singapore. Int. J. Auditing. 5(2):103-25

18.Cooper BJ, Leung Philomena, Mathews Clive (1994) Internal audit: An Australian profile. Managerial Auditing Journal 9(3):13-9.

19. Nachmias David (1996) Research Methods in the social sciences, $5^{\text {th }}$ Edition. London, UK: St Martins Press Inc.

20.Kline P (1999) The handbook of psychological testing (2nd ed.). London: Routledge.

21.Gravetter Forzano (2009) Research Methods for Behavioral Sciences, $3^{\text {rd }} E d$. USA: Wadsworth Cengage Learning, p 352.

22. Holloway Immy (1997) Basic concepts for Qualitative Research. Carton Victoria, Australia: Blackwell science ltd, p 99.

23.Kerlinger FN (1970) Foundations of Behavioral Research. New York, USA: Holt, Rinehart and Winston, p 8.

24.Leedy RD (1989) Practical Research: Planning and Design, $4^{\text {th }}$ Edition. London, UK: Collier Macmillan, $p$ 5 . 